\title{
Perceived Inadequacy: A Study of the Imposter Phenomenon among College and Research Librarians
}

\section{Melanie Clark, Kimberly Vardeman, and Shelley Barba}

The Imposter Phenomenon (IP) is an observed anxiety caused by an individual's feelings of fraudulence, fear of being exposed as a fraud, and inability to internalize personal achievement. This study measures the incidence of the IP among librarians at college and research institutions in the United States and Canada and seeks to identify factors that contribute to its frequency. One in eight librarians reported above average IP scores. Younger librarians and those with less longevity experience IP feelings at a higher rate than more experienced counterparts. Also included is a discussion of how to lessen the impact of IP feelings.

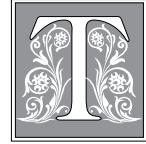

he tasks of a modern librarian within an organization are fluid and often an amalgamation of vastly different roles such as educator, social worker, IT professional, and printer troubleshooter. Striving to be seen as an authoritative figure can lead to internal conflict when the librarian does not feel he or she is knowledgeable or experienced with the subject at hand. Furthermore, college and university librarians often serve as liaisons to faculty with more education and experience, which can exacerbate those feelings. This culture of academia can foster professional anxiety in which individuals question their merit. ${ }^{1}$

The term "Imposter Phenomenon" (IP) is used to describe the feelings an individual experiences when he or she rightfully achieves a level of success but does not feel deserving of said success. ${ }^{2}$

Joan Harvey and Cynthia Katz outlined the three main signs of the IP:

1. Believing that one has fooled others into overestimating one's own abilities.

2. Attributing personal success to factors other than one's ability or intelligence, such as luck, extra work, charisma, or evaluator's misjudgment.

3. Fearing exposure as an imposter. ${ }^{3}$ The individual's fear of being discovered as an imposter by supervisors leads to anxiety, lack of confidence, and other psychological distress. The IP begins to damage a person's quality of life when it inhibits job performance and satisfaction.

Melanie Clark is Architecture Image Librarian, Kimberly Vardeman is Reference Librarian, and Shelley Barba is Metadata Librarian at Texas Tech University; e-mail: melanie.clark@ttu.edu, kimberly.vardeman@ ttu.edu, shelley.barba@ttu.edu. (C) 2014 Melanie Clark, Kimberly Vardeman, and Shelley Barba, AttributionNonCommercial (http://creativecommons.org/licenses/by-nc/3.0/) CC BY-NC 
Due to a dearth of published studies about the IP in libraries, its impact on librarianship is largely unknown. This study reports the incidence of the IP among librarians at college and research institutions in the United States and Canada, identifies factors that contribute to its frequency, and offers suggestions on how librarians and their supervisors can address the effects of the IP.

\section{Review of Selected Literature}

Clance and Imes first defined the term "Imposter Phenomenon" over thirty years ago to describe feelings of perceived fraudulence among high-achieving women. ${ }^{4}$ Although early studies of the phenomenon isolated it as a problem among high-achieving women, subsequent research showed that men experience these feelings at a comparable rate and that gender is not a contributing factor. ${ }^{5}$ Although they provided no normative data about the general population, Harvey and Katz estimated that 70 percent of the general population has felt imposter tendencies with regard to their work during some part of their careers. ${ }^{6}$ More recent research has examined various aspects of the phenomenon in specific populations.

Much IP research has focused on identifying which personality variables contribute to the phenomenon. Kolligian and Sternberg reported that the IP, or as they termed it, "perceived fraudulence," is associated with tendencies toward depression, self-criticism, social anxiety, and high pressure to achieve. ${ }^{7}$ McGregor, Gee, and Posey proposed that those with imposter feelings are more likely to suffer the symptoms of depression, and these combined feelings may hinder productivity. ${ }^{8}$ Kets de Vries argued that perfectionism transforms imposter fears into actual self-defeating behaviors. Those who perceive themselves as imposters set impossibly high goals and then overwork themselves in an effort to counterbalance supposed deficiencies. Failure to achieve their excessively high goals causes further feelings of doubt and fraudulence, increasing the tendency to overwork and triggering burnout. ${ }^{9}$

Bernard, Dollinger, and Ramaniah explored the connections between the "Big Five" dimensions of personalityNeuroticism, Extraversion, Openness to Experience, Agreeableness, and Conscientiousness - and the IP. They found a strong correlation between the IP and manifestations of Neuroticism such as self-doubt, depression, and anxiety. Their research also showed a correlation between the IP and a lack of Conscientiousness or self-discipline. ${ }^{10}$ Some researchers have hypothesized that IP tendencies will be found among those who self-handicap, meaning that they set up obstacles to prevent success, to protect their self-esteem. ${ }^{11}$ Self-handicapping behaviors relating to employment include job hopping, perfectionism, overworking, procrastination, and inability to delegate. ${ }^{12}$ Ross and Krukowski also found a strong correlation between IP tendencies and dependent personality, detached personality, and negative entitlement. ${ }^{13}$

The literature is replete with articles about the IP among academics, but there is very little discussion of the IP among librarians. Diane Zorn stated that the competitive, isolating culture of higher education contributes to imposter feelings, ${ }^{14}$ while Kets de Vries theorized that there is a higher incidence of the IP in academia because the appearance of intelligence is key to personal success. ${ }^{15}$ Parkman and Beard suggested that, because individuals experiencing the IP may have the tendency to burn out and leave an organization rather than risk being found out as a fraud, the IP negatively impacts employee retention and succession planning in higher education. ${ }^{16}$

While there have been no formal studies of the IP specifically among librarians, the concept is not completely absent from library literature. Rachel Singer Gordon identified systems librarians as a group more apt to experience feelings of being an imposter because that area of librarianship involves a high level of 
technical knowledge and the need to deal with constant technological change. She recommended that systems librarians minimize those feelings by emphasizing the skills they bring to systems jobs. ${ }^{17}$ Due to constant changes in the nature of their work, and proliferation of responsibilities and roles, academic librarians in all positions face similar work challenges.

Without using the phrase "imposter phenomenon," recent studies and articles on changing roles of all librarians point to individual librarians' lack of selfconfidence and authority. ${ }^{18}$ Newhouse and Spisak expressed that "this feeling of inadequacy... where training is often minimal and expectations of new librarians are high, is an important problem for the profession."19

\section{Research Questions}

After observing some of the signs of imposter feelings in new librarians and discovering that very little had been published about the prevalence of the IP among librarians, the researchers embarked on a study to test three hypotheses:

- Hypothesis 1: Newer academic librarians in the United States and Canada exhibit a higher occurrence of IP feelings than more experienced librarians.

- Hypothesis 2: Younger academic librarians in the United States and Canada exhibit a higher occurrence of IP feelings than older librarians.

- Hypothesis 3: Librarians in positions requiring technical expertise have a higher occurrence of IP feelings than those requiring more traditional librarian skill sets.

This study addressed the following research questions to evaluate the researchers' hypotheses:

- Question 1: Does the IP occur consistently among librarians?

- Question 2: Does it occur at a higher incidence among younger or newer librarians?
- Question 3: What other demographic factors are associated with its frequency?

\section{Methodology}

The researchers created a self-report questionnaire and submitted it for evaluation by the researchers' Institutional Review Board. The questionnaire was distributed as an e-survey using Survey Monkey and opened for participants during the summer of 2011.

The questionnaire consisted of a demographic profile, the Harvey Imposter Phenomenon Scale, and three additional questions. The questionnaire took approximately 10-20 minutes to complete. The Appendix of this article contains the text of the survey.

A demographic profile collected information about the subjects' age, gender, career longevity, employment classification, education level, job function, and geographical region. These variables were collected in order to identify correlations between IP feelings and specific demographics.

The Harvey IP scale is a widely used self-report questionnaire developed by psychologist Joan Harvey to validate the IP as a psychological construct. The 14 items of the scale are ranked on a 7-point Likert-type scale ranging from "not all true" to "very true." The total IP score is on a range of 0 to 84 . Various researchers report an internal consistency reliability between .73 and $.91 .^{20}$

The researchers distributed the online survey through e-mail solicitation to librarians employed at Association of Research Libraries institutions, libraryrelated listserv announcements, and personal interactions at the American Library Association 2011 Annual Conference.

\section{Participants}

From 445 voluntary responses to the e-survey, the researchers filtered the sample to include only librarians holding a master's in library science or equivalent and employed at college and university 
libraries in North America. In all, 352 respondents met the criteria. There were 262 female respondents in the sample $(74.4 \%)$, and 90 male respondents $(25.6 \%)$. The majority of respondents ( $n=219,62.2 \%)$ were over 40 years of age, and the youngest age group (30 or under) was the least represented ( $n=32,9.1 \%$ ). Additional demographics of these respondents are shown in table 1.

The job function demographics gathered from the survey proved to be unreliable because of the multifunctional nature of many librarians' job descriptions. Although the largest group of respondents identified themselves as reference librarians, the second largest group chose "Other" and listed multiple job functions in the open-ended comment field. Because of the possibility that some respondents who selected only one job function actually performed several, the researchers considered the data not reliable enough for analysis.

\section{Results}

The highest possible score on the Harvey IP Scale is 84 , and lowest is 0 . Harvey stated that scores in the middle range (in the vicinity of 42 points) indicate possible troubles due to imposter feelings, and scores in the upper range suggest significant anxiety. To analyze results, the researchers chose the score of 42 as a benchmark to show the percentage of participants who likely struggle with IP feelings to a significant degree. ${ }^{21}$ The overall sample had a mean IP score of 28.42 with a standard deviation of 12.47 and a range of 3-70 (see table 2).

These results suggest that 1 in 8 librarians may be experiencing IP feelings to a significant degree. The additional short-answer responses support this finding. In answer to the question, "Do you struggle

\begin{tabular}{|c|c|c|}
\hline \multicolumn{3}{|c|}{$\begin{array}{c}\text { TABLE } 1 \\
\text { Demographics of Respondents }(\mathrm{N}=352)\end{array}$} \\
\hline Characteristic & n & $\begin{array}{c}\text { Percentage } \\
\text { of Total } \\
\text { Responses }\end{array}$ \\
\hline \multicolumn{3}{|l|}{ Age } \\
\hline 30 years or under & 32 & 9.1 \\
\hline $31-35$ years & 54 & 15.3 \\
\hline 36-40 years & 48 & 13.6 \\
\hline $41-50$ years & 67 & 19.0 \\
\hline $51-60$ years & 97 & 27.6 \\
\hline 61 years or over & 54 & 15.3 \\
\hline \multicolumn{3}{|l|}{ Gender } \\
\hline Male & 90 & 25.6 \\
\hline Female & 262 & 74.4 \\
\hline \multicolumn{3}{|l|}{ Longevity } \\
\hline Less than 3 years & 48 & 13.6 \\
\hline $3-6$ years & 49 & 13.9 \\
\hline $6-10$ years & 53 & 15.0 \\
\hline 10-20 years & 90 & 25.6 \\
\hline More than 20 years & 112 & 31.8 \\
\hline \multicolumn{3}{|l|}{ Employment Classification } \\
\hline Staff & 87 & 24.7 \\
\hline Faculty, non-tenure-track & 79 & 22.4 \\
\hline Faculty, tenure-track & 186 & 52.8 \\
\hline \multicolumn{3}{|l|}{ Education Level } \\
\hline $\mathrm{PhD}$ & 32 & 9.1 \\
\hline MLS and other Master's & 126 & 35.8 \\
\hline MLS & 184 & 52.3 \\
\hline Master's, other than MLS & 10 & 2.8 \\
\hline \multicolumn{3}{|l|}{ Region } \\
\hline US Southwest & 44 & 12.5 \\
\hline US West & 40 & 11.4 \\
\hline US South & 89 & 25.3 \\
\hline US Midwest & 100 & 28.4 \\
\hline US Northeast & 51 & 14.5 \\
\hline Canada & 25 & 7.1 \\
\hline Other & 3 & .9 \\
\hline
\end{tabular}




\begin{tabular}{|c|c|c|c|c|}
\hline \multicolumn{5}{|c|}{ TABLE 2 } \\
\hline \multicolumn{2}{|c|}{ Total IP Scores (Range=0-84; N=352) } \\
\hline High & Low & Median & Average & $\begin{array}{c}\text { No. }(\%) \text { of } \\
\text { scores over 42 }\end{array}$ \\
\hline 70 & 3 & 27 & 28.42 & $45(12.78)$ \\
\hline
\end{tabular}

quently for feelings of inadequacy in the survey responses: a lack of experience or training, a new position, or an emphasis on new technology in the workplace. The combination of the IP scale scores and the shortanswer responses paint an overall with feelings of inadequacy at your job on a regular basis?" 60 (17.5\%) of the 343 respondents answered that they do, $202(58.9 \%)$ answered that they do not, and $81(23.6 \%)$ responded that they do not presently, but have in the past. One librarian who answered that he or she does struggle with feelings of inadequacy explained, "I'm in a new position having to learn a lot of new things with little guidance. I definitely feel inadequate on a regular basis-I'm hoping this situation will improve as time passes."

The same respondent, answering to what he or she attributed those feelings, said, "Sometimes it seems as though our field is changing so fast that it is difficult to feel truly competent at everything needed to do the job well. Not to mention that many of us wear so many hats that we're bound to feel like one of those hats doesn't fit as well as the others." This respondent's answers reflect the reasons given most frepicture of the prevalence of IP feelings.

Differences between gender scores were not significant. Females in this study had a mean score of 28.30 while males had a mean score of 28.78 (see table 3 ). This finding was in line with previous research with gender and incidence of the IP. ${ }^{22}$

Table 4 shows that, as age increases, average IP scores decrease. Twenty-five percent of the respondents age 30 or under reported IP scores over 42. Since the average IP score for this group is near the midrange of the scale, one might predict that significant numbers of young librarians experience moderate to severe imposter feelings. One respondent said, "I've felt like I was underqualified, but it mostly stemmed because I was young, and my superiors tended to passiveaggressively treat me as if I wasn't very qualified."

Librarians in the first three years of employment reported significantly higher

\section{TABLE 3}

IP Scores by Gender $($ Range $=0-84 ; \mathbf{N}=352)$

\begin{tabular}{|l|c|c|c|c|c|}
\hline Gender & High & Low & Median & Average & No. (\%) of scores over 42 \\
\hline Male $(\mathrm{n}=90)$ & 70 & 7 & 25.5 & 28.78 & $14(15.56)$ \\
\hline Female $(\mathrm{n}=262)$ & 64 & 3 & 28 & 28.30 & $31(11.83)$ \\
\hline
\end{tabular}

\begin{tabular}{|l|c|c|c|c|c|}
\hline \multicolumn{7}{|c|}{ TABLE 4 } \\
\hline IP Scores by Age (Range=0-84; N=352) \\
\hline High & Low & Median & Average & $\begin{array}{c}\text { No. (\%) of scores } \\
\text { over 42 }\end{array}$ \\
\hline 30 years or under $(\mathrm{n}=32)$ & 70 & 7 & 34 & 35.34 & $8(25)$ \\
\hline $31-35$ years $(\mathrm{n}=54)$ & 63 & 7 & 30 & 30.48 & $11(20.37)$ \\
\hline $36-40$ years $(\mathrm{n}=48)$ & 59 & 8 & 25 & 27.92 & $8(16.67)$ \\
\hline $41-50$ years $(\mathrm{n}=67)$ & 57 & 4 & 28 & 29.07 & $7(10.45)$ \\
\hline $51-60$ years $(\mathrm{n}=97)$ & 58 & 3 & 25 & 26.81 & $8(8.25)$ \\
\hline 61 years or over $(\mathrm{n}=54)$ & 64 & 4 & 23 & 24.80 & $3(5.56)$ \\
\hline
\end{tabular}




\begin{tabular}{|l|c|c|c|c|c|}
\hline \multicolumn{7}{|c|}{ TABLE 5 } \\
\hline IP Scores by Longevity (Range=0-84; N=352) \\
\hline & High & Low & Median & Average & $\begin{array}{c}\text { No. (\%) of scores } \\
\text { over 42 }\end{array}$ \\
\hline Less than 3 years $(\mathrm{n}=48)$ & 70 & 7 & 34 & 35.21 & $14(29.17)$ \\
\hline $3-6(\mathrm{n}=49)$ & 60 & 4 & 30 & 29.94 & $8(16.33)$ \\
\hline $6-10(\mathrm{n}=53)$ & 52 & 7 & 25 & 26.02 & $4(7.55)$ \\
\hline $10-20(\mathrm{n}=90)$ & 58 & 7 & 27 & 28.53 & $12(13.33)$ \\
\hline More than 20 $(\mathrm{n}=112)$ & 64 & 3 & 24.5 & 25.90 & $7(6.25)$ \\
\hline
\end{tabular}

IP scores than their more experienced colleagues. Twenty-nine percent of these respondents reported scores over 42 (see table 5). One respondent stated that, although feelings of inadequacy lessened with age, new positions still contributed to these feelings: "When I first started my career, and at my second job at the beginning, it took a while to gain confidence in my abilities. Now, over 10 years in, if I don't think I can handle something or learn how to take it on, I'm more than happy to admit that from the start."

Employment classification was not a significant predictor of IP scores (see table 6). However, when analyzing em- ployment classification combined with longevity, both faculty groups with less than three years of longevity reported significantly higher IP scores than the corresponding librarians classified as staff (see tables 7-9). Furthermore, librarians in tenure-track positions with this level of longevity had higher IP scores than non-tenure-track librarians with the same level of longevity. There was a significant drop in percentages of high scores among tenure-track faculty librarians with six to ten years of longevity compared to those with only three to six years (from $23 \%$ to $4 \%$ ). Whether this decrease is due to those librarians achieving tenure or another

\begin{tabular}{|l|c|c|c|c|c|}
\hline \multicolumn{7}{|c|}{ TABLE 6 } \\
\hline IP Scores by Employment Classification (Range=0-84; N=352) \\
\hline Employment Classification & High & Low & Median & Average & $\begin{array}{c}\text { No. (\%) of scores } \\
\text { over 42 }\end{array}$ \\
\hline Staff (n=87) & 58 & 4 & 27 & 27.49 & $9(10.34)$ \\
\hline Faculty, non-tenure-track (n=79) & 64 & 4 & 27 & 28.22 & $10(12.66)$ \\
\hline Faculty, tenure-track (n=186) & 70 & 3 & 28 & 28.95 & $26(13.98)$ \\
\hline
\end{tabular}

TABLE 7

IP Scores by Longevity and Employment Classification (Staff only) (Range $=0-84 ; \mathrm{N}=87$ )

\begin{tabular}{|l|c|c|c|c|c|}
\hline Longevity (staff only) & High & Low & Median & Average & $\begin{array}{c}\text { No. }(\%) \text { of } \\
\text { scores over 42 }\end{array}$ \\
\hline Less than 3 years $(\mathrm{n}=18)$ & 48 & 13 & 34 & 31.8 & $3(16.67)$ \\
\hline 3-6 years $(\mathrm{n}=14)$ & 56 & 4 & 26.5 & 27.6 & $3(21.43)$ \\
\hline 6-10 years $(\mathrm{n}=12)$ & 35 & 8 & 24 & 23.4 & $0(0)$ \\
\hline 10-20 years $(\mathrm{n}=24)$ & 58 & 10 & 24 & 25.4 & $1(4.16)$ \\
\hline More than 20 years $(\mathrm{n}=19)$ & 46 & 10 & 31 & 28.5 & $2(10.53)$ \\
\hline
\end{tabular}




\begin{tabular}{|l|c|c|c|c|c|}
\hline \multicolumn{7}{|c|}{ TABLE 8 } \\
IP Scores by Longevity and Employment Classification \\
(Faculty, non-tenure-track only) (Range=0-84; N=79)
\end{tabular}

\begin{tabular}{|c|c|c|c|c|c|}
\hline \multicolumn{6}{|c|}{$\begin{array}{c}\text { TABLE } 9 \\
\text { IP Scores by Longevity and Employment Classification } \\
\text { (Faculty, tenure-track only) (Range }=0-84 ; \mathrm{N}=186)\end{array}$} \\
\hline $\begin{array}{l}\text { Longevity (Faculty, tenure-track } \\
\text { only) }\end{array}$ & High & Low & Median & Average & $\begin{array}{c}\text { No. }(\%) \text { of } \\
\text { scores over } 42\end{array}$ \\
\hline Less than 3 years $(n=17)$ & 70 & 7 & 38 & 37.69 & $7(41.18)$ \\
\hline $3-6$ years $(n=22)$ & 60 & 11 & 33.5 & 32.14 & $5(22.73)$ \\
\hline $6-10$ years $(n=26)$ & 47 & 7 & 25 & 25.23 & $1(3.85)$ \\
\hline $10-20$ years $(n=52)$ & 57 & 8 & 28.5 & 29.10 & $9(17.31)$ \\
\hline More than 20 years $(n=69)$ & 64 & 3 & 25 & 26.59 & $5(7.25)$ \\
\hline
\end{tabular}

factor is worth investigating in further research. Multiple respondents attributed feelings of inadequacy to the rigors of tenure, for example: “Workload interfer[es] with tenure-track responsibilities and [I am not] able to devote $100 \%$ to any project because of those competing demands on my time and resources."

Concerning education levels, the differences between the respondents' average scores were not significant (see table 10). The discrepancy in percentages of scores over 42 could be due to the uneven distribution of education levels of the re- spondents, specifically the small sample sizes of PhD holders and those without an MLS. There is no notable difference between groups by geographic region (see table 11).

\section{Statistical Analysis}

Analysis of variance (ANOVA), regression analysis, and hierarchical regression were used to look in more depth at how the demographics of age, employment classification, and longevity are related to the strength of the IP in our sample.

\begin{tabular}{|l|c|c|c|c|c|}
\hline \multicolumn{7}{|c|}{ TABLE 10 } \\
IP Scores by Education Level (Range=0-84; N=352) \\
\hline Education Level & High & Low & Median & Average & $\begin{array}{c}\text { No. (\%) of } \\
\text { scores over 42 }\end{array}$ \\
\hline PhD (n=32) & 64 & 9 & 27.5 & 27.72 & $2(6.25)$ \\
\hline MLS and other Master's (n=126) & 60 & 4 & 26 & 28.02 & $16(12.70)$ \\
\hline MLS (n=184) & 70 & 3 & 28 & 28.82 & $27(14.67)$ \\
\hline Master's, other than MLS (n=10) & 40 & 15 & 28 & 28.40 & $0(0)$ \\
\hline
\end{tabular}




\begin{tabular}{|l|c|c|c|c|c|}
\hline \multicolumn{7}{|c|}{ TABLE 11 } \\
\hline Region & High & Low & Median & Average & $\begin{array}{c}\text { No. (\%) of scores } \\
\text { over 42 }\end{array}$ \\
\hline US Southwest $(\mathrm{n}=44)$ & 63 & 8 & 28.5 & 30.52 & $10(22.73)$ \\
\hline US West $(\mathrm{n}=40)$ & 60 & 3 & 29 & 30.13 & $8(20)$ \\
\hline US South $(\mathrm{n}=89)$ & 70 & 8 & 28 & 28.79 & $9(10.11)$ \\
\hline US Midwest $(\mathrm{n}=100)$ & 64 & 4 & 27 & 28 & $14(14)$ \\
\hline US Northeast $(\mathrm{n}=51)$ & 58 & 4 & 26 & 25.57 & $2(3.92)$ \\
\hline Canada (n=25) & 52 & 11 & 31 & 29.48 & $2(8)$ \\
\hline Other $(\mathrm{n}=3)$ & 22 & 11 & 21 & 18 & $0(0)$ \\
\hline
\end{tabular}

Since age (30 or under, 31-35, 36-40, $41-50,51-60$, and 61 or over) and employment classification (Faculty, tenure-track; Faculty, non-tenure-track, and Staff) were ordinal and nominal variables, respectively, spanning unequal ranges, these variables were dummy coded, and a linear regression was used to analyze their effects on participants' scores on the IP scale. A hierarchical regression was calculated to analyze each of these effects.

Employment classification was entered in the first step of the hierarchical regression. There were not significant differences in participants' scores on the imposter phenomenon scale due to their employment classification $\left[\mathrm{R}^{2}=.004, F(2\right.$, 348) $=.773, p=.462]$.

Age was entered into the second step of the hierarchical regression and participants' scores on the IP scale were found to differ among age groups $\left[\mathrm{R}^{2}=.045\right.$, $\mathrm{F}(5,343)=3.251, p=.007]$. The mean IP scores between the youngest (30 or under) and oldest (61 or over) age groups were contrasted and found to be significantly different $[\beta=.183, \mathrm{t}(350)=3.292, p=.001]$; however, when the youngest and midage (41-50) were contrasted, they were not found to be significantly different $[\beta=.010, \mathrm{t}(350)=0.180, p=.858]$. As a whole, age accounted for 4.5 percent of the variance in imposter phenomenon scores, suggesting that younger subjects were more likely to have a higher IP score than their older counterparts (see table 3).

The interaction between participants' employment classification and age was entered in the third step of the hierarchical regression. The interaction was found to be a significant unique predictor of participants' scores on the IP scale $\left[\mathrm{R}^{2}=.050\right.$, $F(10,333)=1.854, p=.051]$. Contrasts between the youngest and oldest ranges and the youngest and mid-age participants who were tenure-track, non-tenure-track, and staff were conducted to explore this interaction.

As shown in figure 1, for tenure-track and non-tenure-track faculty participants, the youngest participants ( 30 or under) had higher scores on the IP scale than did their oldest counterparts (61 or over) $[\beta=.202, t(184)=2.702, p=.008$ (Faculty, tenure-track), and $\beta=.331, t(78)=2.700$, $p=.009$ (Faculty, non-tenure-track)]. However, for tenure- and non-tenuretrack participants, younger participants scored no differently on the IP scale than did their mid-age counterparts (41-50) $[\beta=.039, t(184)=.527, p=.599$ (Faculty, tenure-track), and $\beta=.150, t(78)=1.220, p$ $=.226$ (Faculty, non-tenure-track)].

This trend is not the same for staff. Younger participants scored significantly higher on the IP scale than did the midage participants $[\beta=.250, t(86)=2.108$, $p=.038]$, but younger participants did not score differently from the oldest participants $[\beta=.008, t(86)=.066, p=$ $.948]$. This surprising result merits fur- 


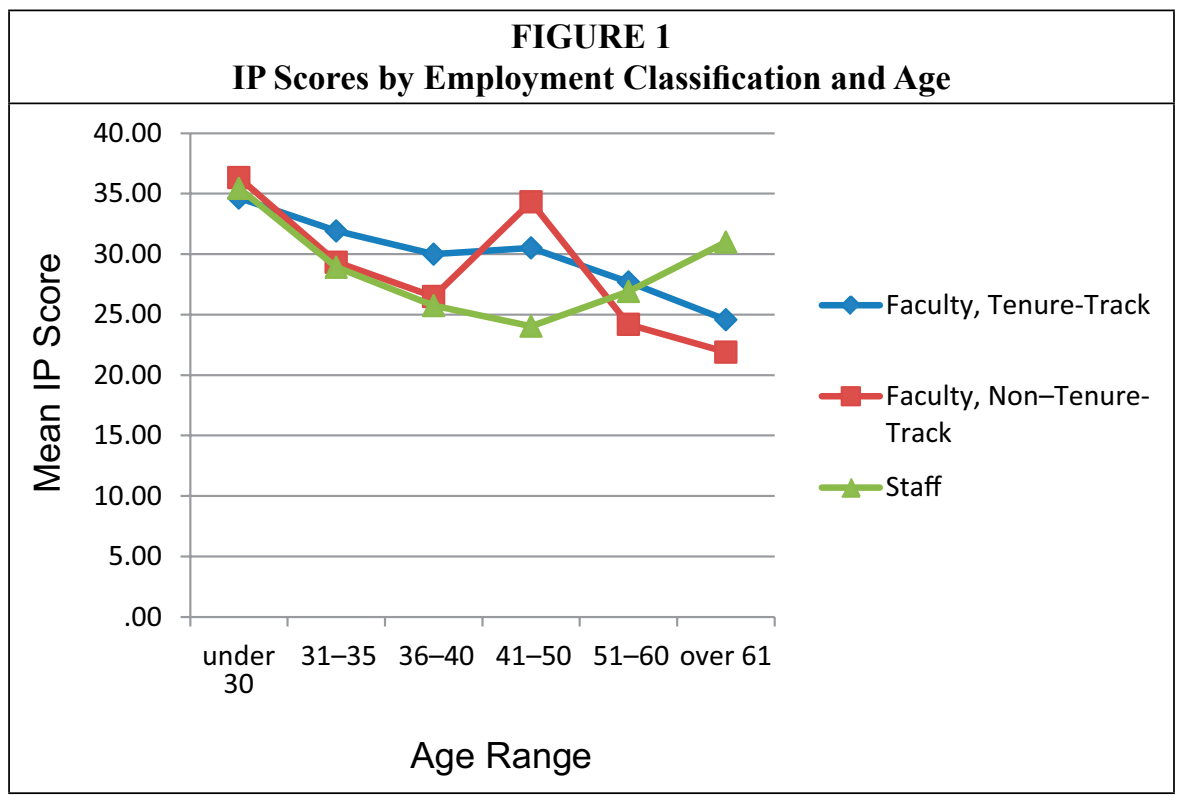

ther investigation through additional research such as subject interviews or a longitudinal study.

A multiple regression was calculated, regressing participants' scores on the IP scale with longevity. Longevity was a categorical variable with five levels (less than 3 years, 3-6 years, 6-10 years, 10-20 years, and more than 20 years); but, for the analysis, these values were dummy coded. As shown in figure 2, significant differences in imposter feelings were found among participants depending on how long they had been working $\left[\mathrm{R}^{2}=\right.$ .061 , F $(4,347)=5.660, p<.001]$. Participants who had been working for less than

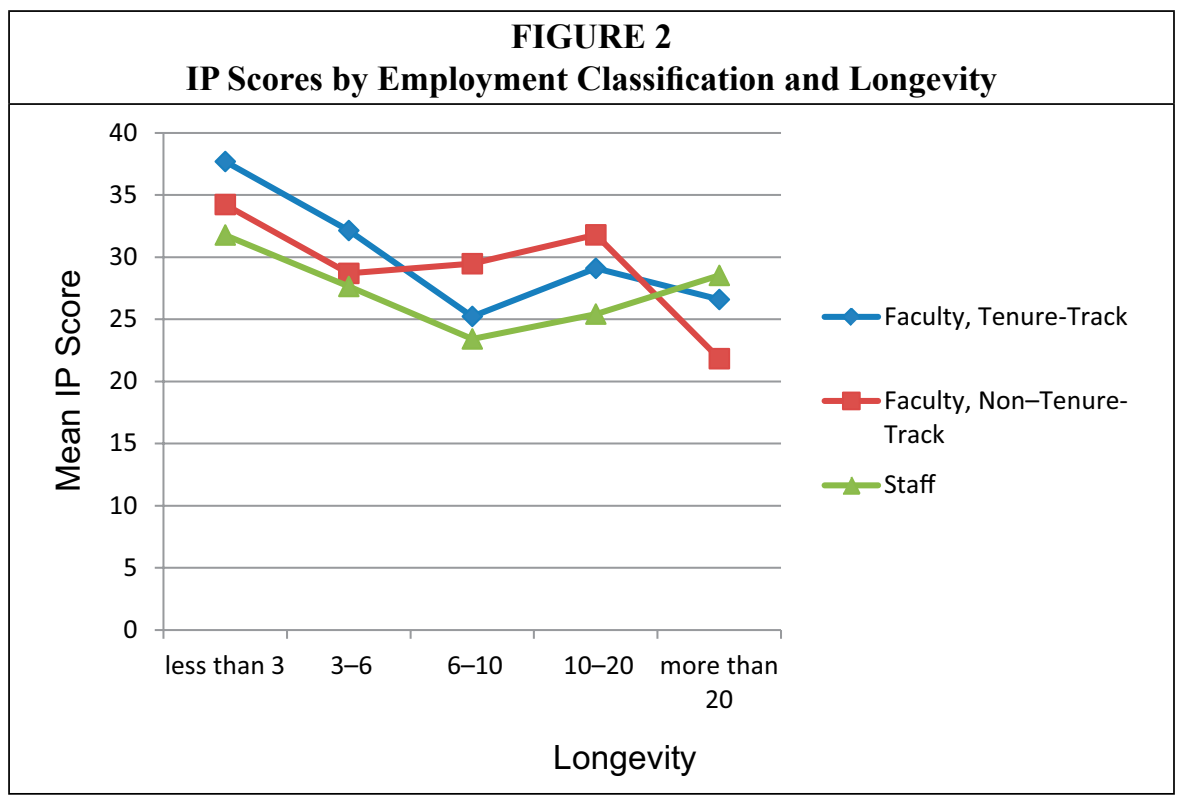


3 years had greater imposter feelings $(\mathrm{M}=35.21, \mathrm{SD}=14.95)$ than did all other participant groups (see table 12). Using a Cramer's $\mathrm{V}$ coefficient test, a significant but weak relationship was found between employment classification and longevity [Cramer's V $=.153$, $\chi 2(8)=16.354, p=.038]$.

\section{Analysis of Additional Questions}

Of 352 survey participants, 343 answered the additional questions following the Harvey IP Scale. In addition to the responses addressed above, respondents attributed their feelings of inadequacy to a variety of professional interactions: a lack of feedback or support from supervisor, negative feedback from supervisor or colleagues, toxic employee relations, lack of training or clear instructions, technological change, and undesired job reassignment or duties.

These comments represent the larger sample. The individual's IP score is included in parentheses:

- "I know objectively that I am good at my job, but I get little to no sincere feedback from my supervisor. This makes me question if my work is really valued by the institution or not." (30)

- "Vague expectations and inconsistent feedback from management and senior colleagues." (35)

- "Now I'm in a position where forward-looking, creative uses of technology are valued. So sometimes I feel old and out-of-date and unable to catch up." (32)

- "I am in a new library technology position. I will often express an opinion and have it met with suspicion or outright disbelief. Then my colleagues will ask someone else in campus IT... before they accept the opinion as reliable. This makes me feel like they think my judgment is inadequate." (53)

\section{TABLE 12}

IP Scores and Longevity

\begin{tabular}{|l|c|c|c|c|c|}
\hline & $\begin{array}{l}\text { Mean } \\
\text { Score }\end{array}$ & SD & B & T & $p$ \\
\hline years & 35.21 & 14.95 & & & \\
\hline rs & 29.94 & 13.1 & 5.27 & 2.136 & .033 \\
\hline ars & 26.02 & 11.16 & 9.19 & 3.80 & $<.001$ \\
\hline years & 28.53 & 11.50 & 6.68 & 3.07 & .002 \\
\hline
\end{tabular}

While library organizations may not necessarily cause IP feelings, survey respondents perceived that the culture fosters those feelings. Some comments from respondents even reflected this culture of animosity for those with feelings of inadequacy in the profession. "Librarianship takes ... flexibility and a firm vision of the future. Loosey-goosey issue-ridden automatons need to find another area of employment."

When asked how feelings of inadequacy affected job performance, respondents reported a tendency to second-guess their work, to strive obsessively for perfection, and to hesitate to stand up for themselves or share their opinions. Approximately 25 percent of respondents who reported having these feelings now or in the past stated that such feelings drove them to work toward building their skills and knowledge; however, most stated that the effects of these feelings were demotivation, procrastination, and feelings of stress, anxiety, or burnout. A selection of responses to this question is included below:

- "Overload paralysis, inaction due to fear of negative reaction from colleagues." (40)

- "I undervalue my accomplishments." (48)

- "This stresses me out considerably and it affects my health as a result." (33)

- "Sometimes I overcompensate and do way to[o] much work, other times I feel so lost I put something off when I don't have to." (52) 
- “They [feelings of inadequacy] challenge me to do my best to learn new ideas." (52)

- "These feelings are major contributors to the level of burnout I currently struggle with." (53)

While not all feelings of inadequacy are necessarily related to the IP, these responses show common reactions to such feelings. This supports the assertion that imposter feelings may lead to self-defeating and self-handicapping behaviors. ${ }^{23}$

\section{Discussion}

The results show that younger librarians and newer librarians reported higher IP scores than their more experienced colleagues. This confirms the researchers' hypotheses about age and longevity being factors in imposter feelings. This finding is not surprising, as older and experienced librarians are usually more familiar with their positions and are likely to feel more secure in their workplace.

The third hypothesis was that librarians in positions requiring technical expertise have a higher occurrence of IP feelings than those requiring more traditional librarian skill sets. Due to inconsistences with the respondents' reports of their job functions and the small pool of responses for each job function category, there was insufficient data to properly test the hypothesis. However, several short-answer responses addressed changing job functions and organizational expectations, including technological change, as contributing to these feelings.

The results also identified other factors associated with higher reported IP scores among respondents. Tenure-track librarians with less than 3 years of longevity experience IP feelings at a higher rate than their non-tenure-track and staff counterparts. This could be partially due to the rigor of the tenure process, but identifying causality is outside the scope of this study. Non-tenure-track faculty with longevity of less than 3 years also experience IP feelings at a high rate, although not as high as tenure-track faculty.
A broad conclusion is that one in eight academic librarians has IP scores above the benchmark of 42. Younger and newer librarians, in particular, may be experiencing significant difficulty because of IP feelings. In addition to having less familiarity with their positions, another cause of these feelings could be the competitiveness, isolation, and other pressures often found in academic culture. ${ }^{24}$ Identifying the reasons why this occurs would require more in-depth research.

Based on previous research ${ }^{25}$ and the short-answer responses, it appears that IP feelings are detrimental to both individuals and the organizations they work for. To assess the impact, further research is needed.

\section{Study Limitations}

As with all research, limitations of this study should be taken into consideration. A concern when analyzing the results of this study is the predominance of female respondents. ARL statistics cite that 37.1 percent of librarians at research institutions (8,329 total) are male, ${ }^{26}$ while only 25.6 percent of this sample is male. Another concern is the difficulty of isolating job functions due to various responses to this question. A large portion of the respondents reported their function as "other," and listed multiple job functions, or uncategorizable positions such as "Subject Specialist." There is no way to verify that librarians who chose a single function do not in reality perform multiple job functions. As a result, the responses to the job function question were unreliable. The study did not consider parallels between the IP and nontraditional librarian roles, such as non-MLS librarians or embedded librarians.

This study may also have a selection bias, as the researchers contacted potential participants with contact information available on their library websites, resulting in a disproportionate number of responses from public services librarians. Furthermore, librarians who do not experience IP feelings might have been 
less likely to complete a questionnaire of this nature.

Self-reporting questionnaires also come with a certain degree of unreliability. The results showed that respondents with above-average scores on the Harvey IP Scale did not always report that they experienced professional anxiety in their answers to the additional questions. Mood variability and degree of selfawareness may influence how a participant answers survey questions.

\section{Conclusion and Recommendations}

There are a number of ways individuals suffering from IP feelings can reduce them. The first step is acknowledging that "feeling incompetent and being incompetent are two different things." 27 Discussing personal performance with peers or a supervisor may help one to gain better perspective. ${ }^{28}$ Clance recommends recording positive feedback. Instead of denying a compliment, "take in the positive response, and ... get as much nourishment as possible out of it." ${ }^{29}$ In extreme cases, counseling or group therapy may be appropriate.

It is normal to experience IP feelings in an unfamiliar environment, but "imposters have trouble putting those feelings in perspective and worry about their errors, not recognizing that their colleagues make them, too. ${ }^{\prime 30}$ Knowing that they are not alone is very beneficial to those who experience IP feelings. Becoming aware of and identifying IP tendencies is also helpful, as is internalizing the belief that imperfection and even failure will not create a disaster. $^{31}$

Supervisors, particularly those who supervise new librarians, should also be aware of the phenomenon. Newhouse and Spisak assert, "the first year seems to make or break new librarians...it takes huge doses of openness and affirmation (...proper training, adherence to the tenets of librarianship, appropriate feedback and rewards, and specific attempts to recruit new professionals) to overcome a new librarian's feelings of being overwhelmed, underappreciated, disillusioned, and underpaid." ${ }^{32}$ The short-answer responses indicate that the relationship between employee and supervisor may play a role in the seriousness of some cases of the IP. Supervisors should look out for employees who downplay their achievements or assert that they are not as good as others think, as this strategy is often used by those with IP feelings to "minimize the implications of poor performance." ${ }^{\prime 3}$ Kets de Vries states, "Good bosses remain alert for symptoms for neurotic imposture in their employees: fear of failure, fear of success, perfectionism, procrastination, and workaholism." 34

Support from supervisors can be beneficial in counteracting the IP. "Providing faculty with opportunities to develop skills in areas they think are their weaknesses can do a lot to reduce anxiety about their abilities and to overcome isolation." ${ }^{35}$ Without having to spend any money at all, supervisors can alleviate imposter anxieties by communicating effectively with their employees. ${ }^{36}$ Emphasizing that constructive criticism is a necessary aspect of a professional job, supervisors should internalize and communicate the belief that "open, honest, critical feedback is an opportunity for new learning and not an irredeemable catastrophe." ${ }^{37}$ Zorn suggests mentoring new faculty to minimize imposter feelings and improve retention. ${ }^{38}$ Formal mentoring may be particularly beneficial in cases in which it is difficult for an employee to discuss their performance with their supervisor.

Valerie Young's book, Secret Thoughts of Successful Women: Why Capable People Suffer from the Impostor Syndrome and How to Thrive in Spite of It, is a recommended resource for individuals experiencing IP feelings, but supervisors may also use it to gain understanding. Exercises in each chapter help readers understand how to overcome fear of success, receive criticism, and better cope with IP feelings.

Further research is also recommended 
to identify other factors contributing to the IP among librarians and to measure the effects of the phenomenon on individual job performance, organization of employ, and the library profession as a whole. This study only measures respondents' IP scores at one point in time. A long-term study with a small sample of subjects to track how IP scores change over time and throughout major career stages would be valuable. Such a study could differentiate between chronic IP feelings and situational instances of IP feelings, such as being a newly hired librarian. Additional research on the IP among librarians would be a further step in raising awareness of its prevalence in the library profession and helping librarians maintain healthy attitudes toward their work environments.

\section{Acknowledgements}

We would like to thank Adam Randell, Jason Coleman, Joy Perrin, and Ian Barba for their constructive feedback on our manuscript. Thank you to Joan Harvey, $\mathrm{PhD}$, for graciously allowing us to use her survey.

\section{Appendix. Librarian's View of Personal Professional Performance}

Thank you for your participation in this study. Participation is voluntary. Questions may be skipped and you may exit the survey at any time. This survey should take approximately 15-20 minutes to complete. Responses will be completely anonymous and kept confidential by the researchers.

1. In what type of library do you work?

College or University (non-ARL)

University (ARL Library)

Public

School

Special (please specify)

2. How is your job classified?

Staff

Faculty, non-Tenure Track

Faculty, Tenure Track

3. Which of the following best describes your primary job function? (Choose one.)

Access Services

Acquisitions

Administration

Cataloging/Metadata

Collection development

Development/fund-raising

Digital services

Distance/distributed education

Electronic resource management

Government documents

Information literacy/instruction

Interlibrary loan/document delivery

Library and information school educator 
Media services/audiovisual

Print Preservation

Rare books and special collections

Reference/research services

Scholarly Communication/repository services

Systems and network services

Web services

Other (please specify)

4. Age range

under $25 \quad 41-50$

26-30 51-60

31-35 over 60

$36-40$

5. Gender

Male

Female

6. Years employed as a professional librarian

Less than 3 years

3 to 6 years

6 to 10 years

10 to 20 years

$20+$ years

7. Highest Education Level

Bachelor's Degree

Master of Library Science, or equivalent

Master's degree in field other than Library Science

Master of Library Science, and Master in another subject

Doctor of Philosophy, any subject

8. Region of employment

Canada

US Northeast

US South

US Midwest

US Southwest

US West

Other 
For each statement below, check the box that best indicates how true of you the statement is. $A=$ not at all true, $\mathrm{G}=$ very true. Your first thoughts and impressions are most important here, so answer as quickly and honestly as possible. ${ }^{39}$

\begin{tabular}{|c|c|c|c|c|c|c|c|}
\hline Statement & $\begin{array}{l}\text { A. } \\
\text { Not at } \\
\text { all true }\end{array}$ & B. & C. & D. & E. & $\mathrm{F}$. & $\begin{array}{l}\text { G. } \\
\text { Very } \\
\text { true }\end{array}$ \\
\hline $\begin{array}{l}\text { 1. In general, people tend to believe I am } \\
\text { more competent than I really am. }\end{array}$ & & & & & & & \\
\hline $\begin{array}{l}\text { 2. I am certain my present level of } \\
\text { achievement results from true ability. }\end{array}$ & & & & & & & \\
\hline $\begin{array}{l}\text { 3. Sometimes I am afraid I will be } \\
\text { discovered for who I really am. }\end{array}$ & & & & & & & \\
\hline $\begin{array}{l}\text { 4. I find it easy to accept compliments about } \\
\text { my competence. }\end{array}$ & & & & & & & \\
\hline $\begin{array}{l}\text { 5. I feel I deserve whatever honors, } \\
\text { recognition, or praise I receive. }\end{array}$ & & & & & & & \\
\hline $\begin{array}{l}\text { 6. At times, I have felt I am in my present } \\
\text { position or academic program through some } \\
\text { kind of mistake. }\end{array}$ & & & & & & & \\
\hline $\begin{array}{l}\text { 7. I feel confident that I will succeed in the } \\
\text { future. }\end{array}$ & & & & & & & \\
\hline 8. I tend to feel like a phony. & & & & & & & \\
\hline $\begin{array}{l}\text { 9. My personality or charm often makes a } \\
\text { strong impression on people in authority. }\end{array}$ & & & & & & & \\
\hline $\begin{array}{l}\text { 10. I consider my accomplishments adequate } \\
\text { for this stage in my life. }\end{array}$ & & & & & & & \\
\hline $\begin{array}{l}\text { 11. In discussions, if I disagree with my boss, a } \\
\text { professor, or the person in charge, I speak out. }\end{array}$ & & & & & & & \\
\hline $\begin{array}{l}\text { 12. I often achieve success on a project, report, } \\
\text { or test when I have anticipated I would fail. }\end{array}$ & & & & & & & \\
\hline $\begin{array}{l}\text { 13. I often feel I am concealing secrets about } \\
\text { myself from others. }\end{array}$ & & & & & & & \\
\hline $\begin{array}{l}\text { 14. My public and private self are the same } \\
\text { person. }\end{array}$ & & & & & & & \\
\hline
\end{tabular}

15. Do you struggle with feelings of inadequacy at your job on a regular basis?
A. No
B. Yes
C. Not presently, but I have in the past

16. If you answered "yes" or "in the past" to the above, to what do you attribute these feelings of inadequacy?

17. How do any feelings of inadequacy affect your job performance, or how have they in the past? 


\section{Notes}

1. Manfred F.R. Kets de Vries, "The Dangers of Feeling like a Fake," Harvard Business Review 83, no. 9 (2005): 108-16.

2. Pauline R. Clance and Suzanne A. Imes, "The Impostor Phenomenon in High Achieving Women: Dynamics and Therapeutic Intervention," Psychotherapy: Theory, Research and Practice 15, no. 3 (1978): 241-47.

3. Joan C. Harvey and Cynthia Katz, If I'm So Successful, Why Do I Feel Like a Fake? The Impostor Phenomenon (New York: St. Martin's Press, 1985), 8.

4. Clance and Imes, "The Impostor Phenomenon in High Achieving Women," 241.

5. Joan C. Harvey, "The Impostor Phenomenon and Achievement: A Failure to Internalize Success" (Ph.D. diss., Temple University, 1981); Mary E.H. Topping and Ellen B. Kimmel, "The Impostor Phenomenon: Feeling Phony," Academic Psychology Bulletin 7 (1985): 213-26; Sharon Fried-Buchalter, "Fear of Success, Fear of Failure, and the Imposter Phenomenon: A Factor Analytic Approach to Convergent and Discriminant Validity," Journal of Personality Assessment 58, no. 2 (1992): 368-79.

6. Harvey and Katz, If I'm So Successful, Why Do I Feel like a Fake? The Impostor Phenomenon, 3; John Gravois, "You're Not Fooling Anyone," Chronicle of Higher Education 54, no. 11 (2007): 1.

7. John Kolligian, Jr., and Robert J. Sternberg, "Perceived Fraudulence in Young Adults: Is There an 'Imposter Syndrome'?" Journal of Personality Assessment 56, no. 2: 308-26.

8. Loretta N. McGregor, Damon E. Gee, and K. Elizabeth Posey, "I Feel like a Fraud and It Depresses Me: The Relation between the Imposter Phenomenon and Depression," Social Behavior and Personality 36, no. 1 (2008): 43-48.

9. Kets de Vries, "The Dangers of Feeling like a Fake," 112.

10. Naijean Bernard, Stephen J. Dollinger, and Nerella V. Ramaniah, "Applying the Big Five Personality Factors to the Impostor Phenomenon," Journal of Personality Assessment 78, no. 2 (2002): 321-33.

11. Scott R. Ross, Jane Stewart, Molly Mugge, and Brandy Fultz, "The Imposter Phenomenon, Achievement Dispositions, and the Five Factor Model," Personality and Individual Differences 31, no. 8 (2001): 1347-55; Kets de Vries, "The Dangers of Feeling like a Fake," 108, 110.

12. Kets de Vries, "The Dangers of Feeling like a Fake," 110-12.

13. Scott R. Ross and Rebecca A. Krukowski, "The Imposter Phenomenon and Maladaptive Personality: Type and Trait Characteristics," Personality and Individual Differences 34, no. 3 (2003): 477-84.

14. Diane Zorn, "Academic Culture Feeds the Imposter Phenomenon," Leaders: The Newsletter for Academic Deans and Department Chairs 21, no. 8 (2005): 1, 8.

15. Kets de Vries, "The Dangers of Feeling like a Fake," 111.

16. Anna Parkman and Roxanne Beard, "Succession Planning and the Imposter Phenomenon in Higher Education," CUPA-HR Journal 59, no. 2 (2008): 29-36.

17. Rachel Singer Gordon, "Overcoming the Systems Librarian Imposter Syndrome," LIBRES: Library and Information Science Research Electronic Journal 13, no. 2 (2003), available online at https:// libres.curtin.edu.au/libres13n2/ess\&op_singer_gordon.htm [accessed 5 January 2010].

18. James G. Neal, "Raised by Wolves: Integrating the New Generation of Feral Professionals into the Academic Library," Library Journal 131, no. 3 (2006): 42-44; Ria Newhouse and April Spisak, "Fixing the First Job," Library Journal 129, no. 13 (2004): 44-46.

19. Newhouse and Spisak, "Fixing the First Job," 45.

20. Chan M. Hellman and Tonia D. Caselman, "A Psychometric Evaluation of the Harvey Imposter Phenomenon Scale," Journal of Personality Assessment 83, no. 2 (2004): 161-66.

21. Harvey and Katz, If I'm So Successful, Why Do I Feel like a Fake? The Impostor Phenomenon, 114 .

22. Harvey, "The Impostor Phenomenon and Achievement: A Failure to Internalize Success"; Topping and Kimmel, "The Impostor Phenomenon: Feeling Phony"; Fried-Buchalter, "Fear of Success, Fear of Failure, and the Imposter Phenomenon."

23. Kets de Vries, "The Dangers of Feeling like a Fake," 110-12; Ross, Stewart, Mugge, and Fultz, "The Imposter Phenomenon, Achievement Dispositions, and the Five Factor Model," 1347-55.

24. Zorn, "Academic Culture Feeds the Imposter Phenomenon," 1.

25. Parkman and Beard, "Succession Planning and the Imposter Phenomenon in Higher Education," 31; Kets de Vries, "The Dangers of Feeling like a Fake," 110, 113-16.

26. Association of Research Libraries, "ARL Annual Salary Survey 2010-2011" (2011), available online at www.arl.org/stats/annualsurveys/salary/sal1011.shtml [accessed 26 June 2012].

27. Lucas Laursen, "No, You're Not an Imposter," Science Career Magazine, Feb. 15, 2008, 
Perceived Inadequacy 271

available online at http://sciencecareers.sciencemag.org/career_development/previous_issues/ articles/2008_02_15/caredit_a0800025 [accessed 6 July 2012].

28. Laursen, "No, You're Not an Imposter."

29. Clance and Imes, "The Impostor Phenomenon in High Achieving Women," 246.

30. Laursen, "No, You're Not an Imposter."

31. Gail Matthews and Pauline Clance, "Treatment of the Impostor Phenomenon in Psychotherapy Clients," Psychotherapy in Private Practice 3, no. 1 (1985): 71-81.

32. Ria Newhouse and April Spisak, "Fixing the First Job," 44.

33. Mark R. Leary, Katharine M. Patton, Amy E. Orlando, and Wendy Wagoner Funk, "The Imposter Phenomenon: Self-perceptions, Reflected Appraisals, and Interpersonal Strategies," Journal of Personality 68, no. 4 (2000): 725-56.

34. Kets de Vries, "The Dangers of Feeling like a Fake," 115.

35. Zorn, "Academic Culture Feeds the Imposter Phenomenon," 8.

36. Michael Harvey, Miriam Moeller, and Alex Williams, "Assessing the Role of the Self-Concept on the Destructive Impact of Obsessive-Compulsive Disorder in Managers," Journal of Applied Social Psychology 41, no. 1 (2011): 82-105.

37. Kets de Vires, "The Dangers of Feeling like a Fake," 116.

38. Zorn, "Academic Culture Feeds the Imposter Phenomenon," 8.

39. Harvey and Katz, If I'm So Successful, Why Do I Feel like a Fake? The Impostor Phenomenon, $110-112$. 